TITLE:

\title{
Asymmetric chroman synthesis via an intramolecular oxy-Michael addition by bifunctional organocatalysts.
}

\section{$\operatorname{AUTHOR}(\mathrm{S})$ :}

Miyaji, Ryota; Asano, Keisuke; Matsubara, Seijiro

\section{CITATION:}

Miyaji, Ryota ... [et al]. Asymmetric chroman synthesis via an intramolecular oxy-Michael addition by bifunctional organocatalysts.. Organic \& biomolecular chemistry 2014, 12(1): $119-122$

\section{ISSUE DATE:}

2014-01-07

URL:

http://hdl.handle.net/2433/192994

\section{RIGHT:}

(C) The Royal Society of Chemistry 2014.; This is not the published version. Please cite only the published version.; この論文は出版社版で ありません。引用の際には出版社版をご確認ご利用ください。 


\title{
ARTICLE
}

Cite this: DOI: $10.1039 /$ xoxxooooox

Received ooth January 2012,

Accepted ooth January 2012

DOI: $10.1039 /$ xoxxooooox

www.rsc.org/

\section{Asymmetric chroman synthesis via an intramolecular oxy-Michael addition by bifunctional organocatalysts}

\author{
Ryota Miyaji, Keisuke Asano* and Seijiro Matsubara*
}

\begin{abstract}
Cinchona-alkaloid-urea-based bifunctional organocatalysts facilitate the catalytic asymmetric synthesis of chroman derivatives via an intramolecular oxy-Michael addition reaction. Phenol derivatives bearing an easily available $(E)-\alpha, \beta$-unsaturated ketone or thioester moiety are useful substrates for the title transformation. This method represents a facile synthesis of various optically active 2-substituted chromans in high yield.
\end{abstract}

\section{Introduction}

Chiral 2-substituted chromans are found in an extremely wide range of bioactive compounds, as typified by vitain $\mathrm{E}$, and their biological actibivities have attracted much attention (Fig. 1). ${ }^{1}$ Thus, the enantioselective synthetic methods toward chroman derivatives are highly demanded; indeed, a number of strategies have been reported, addressing this need. ${ }^{2-5}$ Among them, the intramolecular oxy-Michael addition is a promising method for constructing the desired framework from easily available phenol derivatives bearing an $\alpha, \beta$-unsaturated carbonyl; the remaining carbonyl group in the product allows for further structural modification, which may lead to the synthesis of various pharmacological compounds. However, only a few examples of such approaches have been reported to date. ${ }^{4,5}$ In addition, most of these strategies display a significant limitation in that the substrate, typically an $\alpha, \beta$-unsaturated ester moiety, must be in its $(Z)$-isomer form, and that the $(Z)$-forms of more electoron-deficient olefins ( $\alpha, \beta$-unsaturated ketones and thioesters) are extremely difficult to prepare by means of simple methods such as Wittig reactions using stabilized ylides (Scheme 1). These problems must be solved to expand the the scope of synthetically accessible chromans.

We have recently established a useful strategy for the asymmetric synthesis of five- or six-membered oxygen heterocycles via intramolecular oxy-Michael addition starting from (E)- $\alpha, \beta$-unsaturated carbonyl substrates (Scheme 2). ${ }^{6,7}$ This method utilizes multipoint substrate recognition by bifunctional organocatalysts through hydrogen bonding; 8,9 the mild characteristics of activation through hydrogen bonding facilitate concerted catalysis efficient for obtaining high enantioselectivity even in rapid intramolecular processes for cycloetherifications. ${ }^{6 \mathrm{~d}}$ The efficiency of this protocol prompted us to explore the use of bifunctional organocatalysts for the intramolecular oxy-Michael addition from phenol derivatives bearing an (E)- $\alpha, \beta$-unsaturated carbonyl moiety. ${ }^{5,10}$ In this study, we present a novel enantioselective synthesis of 2substituted chromans via intramolecular oxy-Michael addition using cinchona-alkaloid-urea-based bifunctional organocatalysts.

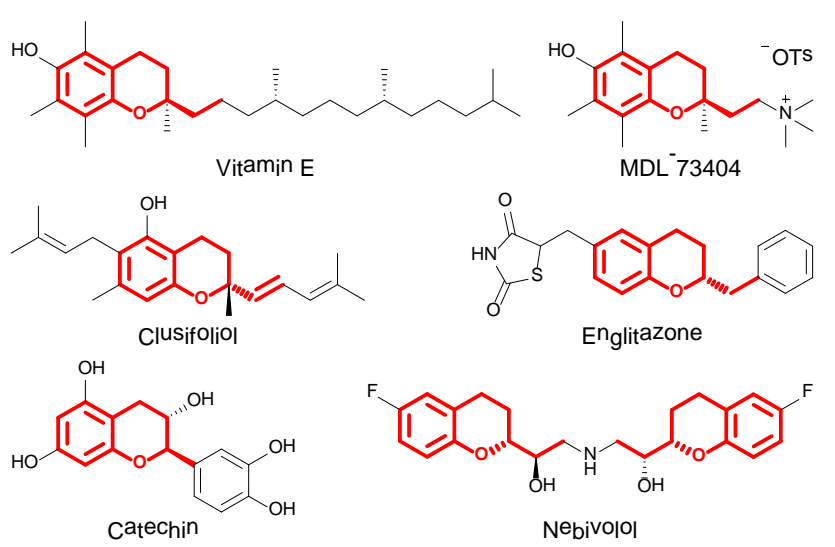

Fig. 1 Representative 2-substituted chromans in bioactive compounds.

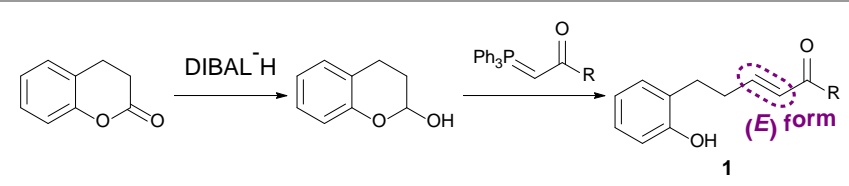

Scheme 1 Facile synthetic route to substrates 1 


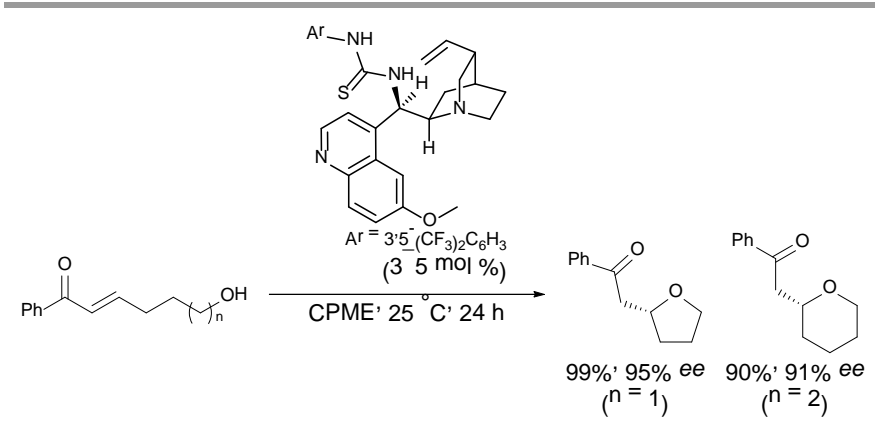

Scheme 2 Asymmetric synthesis of 2-substituted THF and THP via intramolecular oxy-Michael addition by bifunctional organocatalyst

\section{Results and discussion}

We initiated our investigations using substrate 1a with 10 mol \% quinidine-derived bifunctional aminourea catalyst 3a in $\mathrm{CH}_{2} \mathrm{Cl}_{2}$ at $25{ }^{\circ} \mathrm{C}$ over $24 \mathrm{~h}$; chroman product 2a was obtained with moderate enantioselectivity (Table 1, entry 1 ). Solvent screening revealed that THF was effective for both enantioselectivity and yield (Table 1, entry 9). A decrease in reaction temperature improved the enantioselectivity (Table 1 , entry 10). However, the use of a smaller amount of catalyst (5 mol \%) led to lower enantioselectivity, which was likely due to the competing non-catalytic reaction (Table 1, entry 11). A time of $12 \mathrm{~h}$ was found to be sufficient for reaction completion, and higher enantioselectivity could be obtained (Table 1, entry 12). In this reaction, the urea catalyst 3a was revealed to be more efficient than the corresponding thiourea catalyst $\mathbf{3 b}$ (Table 1, entries 12 and 13). ${ }^{7 a}$ Further screening of urea catalysts showed that quinine-derived 3d was an efficient catalyst for obtaining the opposite enantiomer of 2a with good enantioselectivity (Table 1, entry 15).

\begin{tabular}{ccccc}
\hline Table 1 Optimization of Conditions ${ }^{a}$ & & \\
\hline
\end{tabular}

${ }^{a}$ Reactions were run using $1 \mathbf{a}(0.1 \mathrm{mmol})$ and the catalyst $(0.01 \mathrm{mmol})$ in the solvent $(0.2 \mathrm{~mL}) .{ }^{b}$ Isolated yields. ${ }^{c} \mathrm{CPME}=$ cyclopentyl methyl ether. ${ }^{d}$ Reactions were run at $0{ }^{\circ} \mathrm{C}$. ${ }^{e}$ Reaction was run using $5 \mathrm{~mol} \%$ of $3 \mathbf{3 a}(0.005$ mmol). ${ }^{f}$ Reactions were run for $12 \mathrm{~h}$.
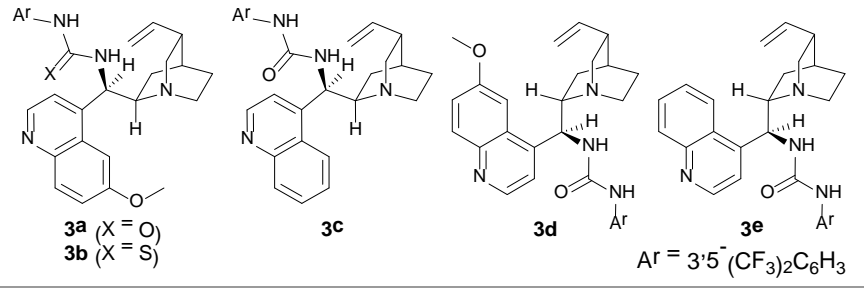

With catalyst 3a and optimized reaction conditions identified, we next investigated the reactions of substrates bearing other (E)-Michael-acceptor moieties. ${ }^{11}$ Electron-rich substrates were also effective, providing the chroman products in high yield and comparable enantioselectivity (Table 2, entries 2 and 3). A starting material bearing an electron-withdrawing group afforded the corresponding product in high yield, although the enantiomeric excess was slightly lower (Table 2, entry 4). A substrate with a p-bromophenyl substituent yielded the corresponding product quantitatively in high enantioselectivity (Table 2, entry 5); however, a 2-naphthyl-substituted enone gave the resultant product in lower yield and stereoselectivity (Table 2, entry 6). Unfortunately, a methylketone proved to be an unsuccessful substrate (Table 2, entry 7). Substituents on the phenol moiety were also investigated, and a substrate with a methoxy group gave the corresponding product in good yield with moderate enantioselectivity (Table 2, entry 8), although a phenol derivative with a bromo group resulted in lower yield and stereoselectivity (Table 2, entry 9). To our delight, an $\alpha, \beta$ unsaturated thioester participated in the cyclization reaction, yielding a chroman derivative suitable for various subsequent transformations, demonstrating the synthetic utility of our method (Scheme 3). The absolute configuration of $\mathbf{2 e}$ was determined as $(R)$ using X-ray analysis (see ESI for details), 
and the configurations of all other examples were assigned accordingly.

Table 2 Scope of $\alpha, \beta$-Unsaturated Ketones ${ }^{a}$

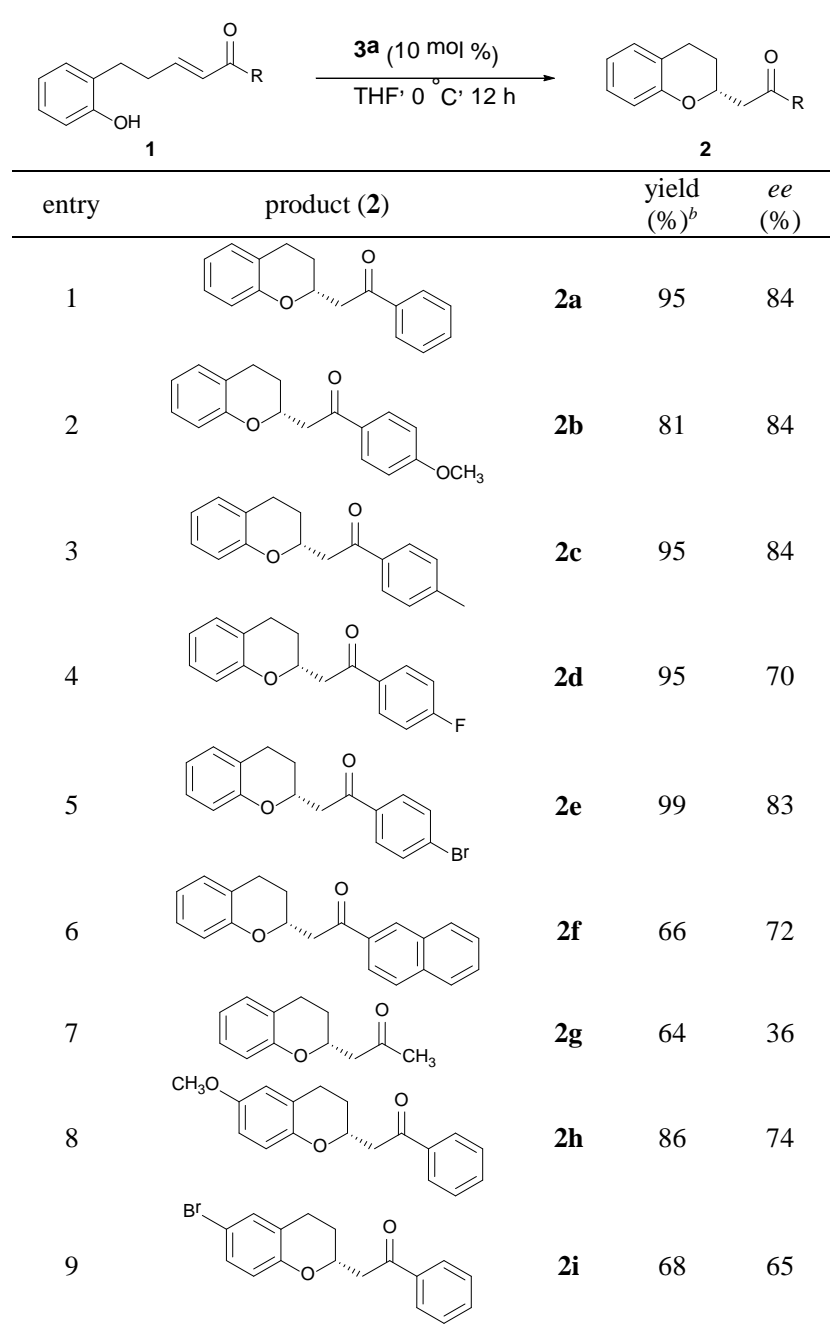

${ }^{a}$ Reactions were run using $1(0.1 \mathrm{mmol})$ and $3 a(0.01 \mathrm{mmol})$ in THF $(0.2$ $\mathrm{mL}) .{ }^{b}$ Isolated yields.

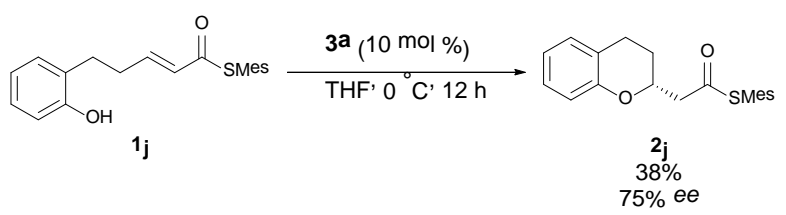

Scheme 3 Reaction of $\alpha, \beta$-Unsaturated Thioester

\section{Conclusions}

In summary, we have presented a novel asymmetric chroman synthesis via intramolecular oxy-Michael addition employing bifunctional aminourea catalysts. In this method, substrates bearing an easily available ( $E$ )-Michael acceptor including $\alpha, \beta$ unsaturated ketones and thioesters could be used, thereby leading to a facile and versatile approach to optically active chromans. Further studies on the expansion of the substrate scope and the application of this methodology toward other heterocyclic scaffolds are currently underway in our laboratory and will be reported in due course.

\section{Acknowledgements}

We thank Professor Takuya Kurahashi (Kyoto University) for $\mathrm{X}$-ray crystallographic analysis. This work was supported financially by the Japanese Ministry of Education, Culture, Sports, Science and Technology.

\section{Notes and references}

Department of Material Chemistry, Graduate School of Engineering, Kyoto University, Kyotodaigaku-Katsura, Nishikyo, Kyoto 615-8510, Japan. E-mail: asano.keisuke.5w@kyoto-u.ac.jp, matsubara.seijiro.2e@kyoto-u.ac.jp; Fax: +81 75383 2438; Tel: +81 75 $3837571,+81753832440$

$\dagger$ Electronic Supplementary Information (ESI) available: Experimental procedures, analytical and spectroscopic data for synthetic compounds, copies of NMR. See DOI: 10.1039/b000000x/

1 For reviews, see: (a) Chromenes, Chromanones, and Chromones, ed. G. P. Ellis, Wiley-Interscience, New York, 1977; (b) Comprehensive Heterocyclic Chemistry II, ed. A. R. Katritzky, C. W. Rees and E. F. V. Scriven, Pergamon, Oxford, 1996.

2 For reviews, see: (a) H. C. Shen, Tetrahedron Lett., 2009, 65, 3931; (b) M. Núñez, P. García, R. F. Moro and D. Díez, Tetrahedron, 2010, 66, 2089.

3 For selected examples, see: (a) Y. Uozumi, K. Kato and T. Hayashi, J. Am. Chem. Soc., 1997, 119, 5063; (b) E. Mizuguchi and K. Achiwa, Chem. Pharm. Bull., 1997, 45, 1209; (c) B. M. Trost and F. D. Toste, J. Am. Chem. Soc., 1998, 120, 9074; (d) B. M. Trost and N. Asakawa, Synthesis, 1999, 1491; (e) B. M. Trost, H. C. Shen and J.-P. Surivet, Angew. Chem., Int. Ed., 2003, 42, 3943; (f) B. M. Trost, H. C. Shen, L. Dong and J.-P. Surivet, J. Am. Chem. Soc., 2003, 125, 9276; ( $g$ ) B. M. Trost, H. C. Shen, L. Dong, J.-P. Surivet and C. Sylvain, J. Am. Chem. Soc., 2004, 126, 11966; (h) J.-R. Labrosse, C. Poncet, P. Lhoste and D. Sinou, Tetrahedron: Asymmetry, 1999, 10, 1069; (i) K. Ishihara, S. Nakamura and H. Yamamoto, J. Am. Chem. Soc., 1999, 121, 4906; (j) S. Nakamura, K. Ishihara and H. Yamamoto, J. Am. Chem. Soc., 2000, 122, 8131; (k) H. Ishibashi, K. Ishihara and H. Yamamoto, J. Am. Chem. Soc., 2004, 126, 11122; (l) L. F. Tietze, K. M. Sommer, J. Zinngrebe and F. Stecker, Angew. Chem., Int. Ed., 2005, 44, 257; (m) L. F. Tietze, F. Stecker, J. Zinngrebe and K. M. Sommer, Chem.-Eur. J., 2006, 12, 8770; (n) K. Liu, A. Chougnet and W.-D. Woggon, Angew. Chem., Int. Ed., 2008, 47, 5827; (o) Y. K. Chung and G. C. Fu, Angew. Chem., Int. Ed., 2009, 48, 2225; (p) L.-Q. Lu, F. Li, J. An, J.-J. Zhang, X.-L. An, Q.-L. Hua and W.-J. Xiao, Angew. Chem., Int. Ed., 2009, 48, 9542; (q) X.-F. Wang, Q.-L. Hua, Y. Cheng, X.-L. An, Q.-Q. Yang, J.-R. Chen and W.-J. Xiao, Angew. Chem., Int. Ed., 2010, 49, 8379; (r) X.-F. Wang, J. An, X.-X. Zhang, F. Tan, J.-R. Chen and W.-J. Xiao, Org. Lett., 2011, 13, 808. (s) L.-Q. Lu, Z.-H. Ming, J. An, C. Li, J.-R. Chen and W.-J. Xiao, J. Org. Chem., 2012, 77, 1072; (t) X.-G. Song, S.-F. Zhu, X.-L. Xie and Q.-L. Zhou, Angew. Chem., Int. Ed., 2013, 52, 2555; (u) H. Wu, Y.-P. 
He and L.-Z. Gong, Org. Lett., 2013, 15, 460; (v) W. Yang, Y. Yang and D.-M. Du, Org. Lett., 2013, 15, 1190; (w) Z.-X. Jia, Y.-C. Luo, X.-N. Cheng, P.-F. Xu and Y.-C. Gu, J. Org. Chem., 2013, 78, 6488;

4 (a) A. Merschaert, P. Delbeke, D. Daloze and G. Dive, Tetrahedron Lett., 2004, 45, 4697; (b) N. Saito, A. Ryoda, W. Nakanishi, T. Kumamoto and T. Ishikawa, Eur. J. Org. Chem., 2008, 2759.

5 Analogous intramolecular oxy-Michael additions to form chromans from $(E)$-substrates by a bifunctional organocatalyst have been recently reported, and the utility is specific to slow reactions from $\alpha, \beta$-unsaturated amides, see: Y. Kobayashi, Y. Taniguchi, N. Hayama, T. Inokuma and Y. Takemoto, Angew. Chem., Int. Ed., 2013, 52, 11114 .

6 (a) K. Asano and S. Matsubara, J. Am. Chem. Soc., 2011, 133, 16711; (b) K. Asano and S. Matsubara, Org. Lett., 2012, 14, 1620; (c) T. Okamura, K. Asano and S. Matsubara, Chem. Commun., 2012, 48, 5076; (d) Y. Fukata, R. Miyaji, T. Okamura, K. Asano and S. Matsubara, Synthesis, 2013, 45, 1627.

7 For our related works on intramolecular aza-Michael addition by bifunctional organocatalysts, see: (a) R. Miyaji, K. Asano and S. Matsubara, Org. Lett., 2013, 15, 3658; (b) Y. Fukata, K. Asano, and S. Matsubara, Chem. Lett., 2013, 42, 355; (c) Y. Fukata, K. Asano and S. Matsubara, J. Am. Chem. Soc., 2013, 135, 12160.

8 (a) T. Okino, Y. Hoashi and Y. Takemoto, J. Am. Chem. Soc., 2003, 125, 12672; (b) T. Okino, Y. Hoashi, T. Furukawa, X. Xu and Y. Takemoto, J. Am. Chem. Soc., 2005, 127, 119; (c) B. Vakulya, S. Varga, A. Csámpai and T. Soós, Org. Lett., 2005, 7, 1967; (d) A. Hamza, G. Schubert, T. Soós and I. Pápai, J. Am. Chem. Soc., 2006, 128, 13151; (e) S. J. Connon, Chem.-Eur. J., 2006, 12, 5418; (f) J.-L. Zhu, Y. Zhang, C. Liu, A.-M. Zheng and W. Wang, J. Org. Chem., 2012, 77, 9813.

9 For reviews on asymmetric catalysis based on hydrogen bonding, see: (a) Hydrogen Bonding in Organic Synthesis, ed. P. M. Pihko, WileyVCH, Weinheim, 2009; (b) A. G. Doyle and E. N. Jacobsen, Chem. Rev., 2007, 107, 5713; (c) M. S. Taylor and E. N. Jacobsen, Angew. Chem., Int. Ed., 2006, 45, 1520.

10 For an example of endo-cyclization via asymmetric intramolecular oxy-Michael addition from phenol derivatives mediated by bifunctional organocatalyst, see: M. M. Biddle, M. Lin and K. A. Scheidt, J. Am. Chem. Soc., 2007, 129, 3830.

11 Although reactions from $\beta$-disubstituted $\alpha, \beta$-unsaturated ketones were also examined, they were less reactive in this catalytic process. See ESI for details (Scheme S1). 